\title{
Las Indias olvidadas
}

Filipinas y América en la cartografía imperial española

As Índias esquecidas: Filipinas e América na cartografia imperial espanhola The forgotten Indies: Philippines and America in the Spanish imperial cartography

\section{Ricardo Padrón}

\section{(2) OpenEdition}

Journals

Edición electrónica

URL: https://journals.openedition.org/terrabrasilis/1141

DOI: 10.4000/terrabrasilis. 1141

ISSN: 2316-7793

\section{Editor}

Rede Brasileira de História da Geografia e Geografia Histórica

\section{Referencia electrónica}

Ricardo Padrón, «Las Indias olvidadas», Terra Brasilis [En línea], 4 | 2015, Publicado el 12 febrero 2015, consultado el 05 diciembre 2022. URL: http://journals.openedition.org/terrabrasilis/1141 ; DOI: https:// doi.org/10.4000/terrabrasilis. 1141

Este documento fue generado automáticamente el 5 diciembre 2022

All rights reserved 


\title{
Las Indias olvidadas
}

\author{
Filipinas y América en la cartografía imperial española \\ As Índias esquecidas: Filipinas e América na cartografia imperial espanhola \\ The forgotten Indies: Philippines and America in the Spanish imperial \\ cartography
}

Ricardo Padrón

Sin duda el mapa mas famoso de las Islas Filipinas producido durante la época colonial es el del padre jesuita Pedro Murillo de Velarde, de 1734. (Figura 1) Su "Carta hydrográphica y chorográphica de las Yslas Filipinas" se imprimió en respuesta a una orden del Rey de España, aunque la rapidez con la cual se cumplió con la orden indica que Murillo Velarde había empezado a trabajar en el mapa bastante antes. Conocido como el primer mapa exacto del archipiélago, y destinado a guiar la navegación por sus arrecifes peligrosos, el mapa también ha servido como un icono de identidad filipina. El mapa fue impreso en Manila misma, por manos de artesanos tagalos, y da testimonio a la habilidad artística y técnica de la imprenta filipina durante el siglo de las luces. Representa las islas a una escala mucho mayor que la de cualquier mapa anterior, y las representa solas, sin incluir otras regiones circundantes, con la excepción de una parte de isla de Borneo. La imagen cartográfica de las islas mismas, luego, queda rodeado por una serie de cuadros, algunos de los cuales ofrecen mapas corográficos de sitios filipinos particulares, otros, escenas típicas de la vida filipina en la ciudad y en el campo, y por fin otros, una serie de tipos étnico -raciales que recuerdan los cuadros de castas mexicanos. Estos cuadros parecen haber sido el trabajo de por lo menos un colaborador filipino, el grabador Nicolás de la Cruz Bagay. El mapa de Murillo Velarde disfrutó de una enorme popularidad, llegando a ser reproducido tanto en libros de historia y geografía como en hojas sueltas, a veces en España pero también en otros países europeos, a veces con atribución a Murillo y a veces no. Estas reproducciones extranjeras solían eliminar la iconografía específicamente española, como las armas borbónicas, y también los cuadros que rodeaban al original, pero la forma original del mapa no cayó en el olvido. En 1921 apareció el mapa entero, con sus cuadros, como parte de un panfleto publicado por el Departamento de Imprenta del gobierno filipino en celebración del cuarto aniversario del descubrimiento de las Islas Filipinas por 
Fernando Magallanes. En 1946, la revista oficial del Falange español sacó una copia facsímil para marcar el reconocimiento por España de la independencia de Filipinas. ${ }^{1}$ De hecho, nos encontramos frente un mapa que transciende por mucho, tanto en su concepción original como en su recepción subsecuente, su función oficial original de carta marítima para guiar la navegación. Nos encontramos frente una obra artística de alta calidad, y de un documento fundacional de la identidad filipina, tanto la criolla como la nacional.

Figura 1: Pedro Murillo Velarde, Carta hydrographica y chorographica de las Ylsas Filipinas

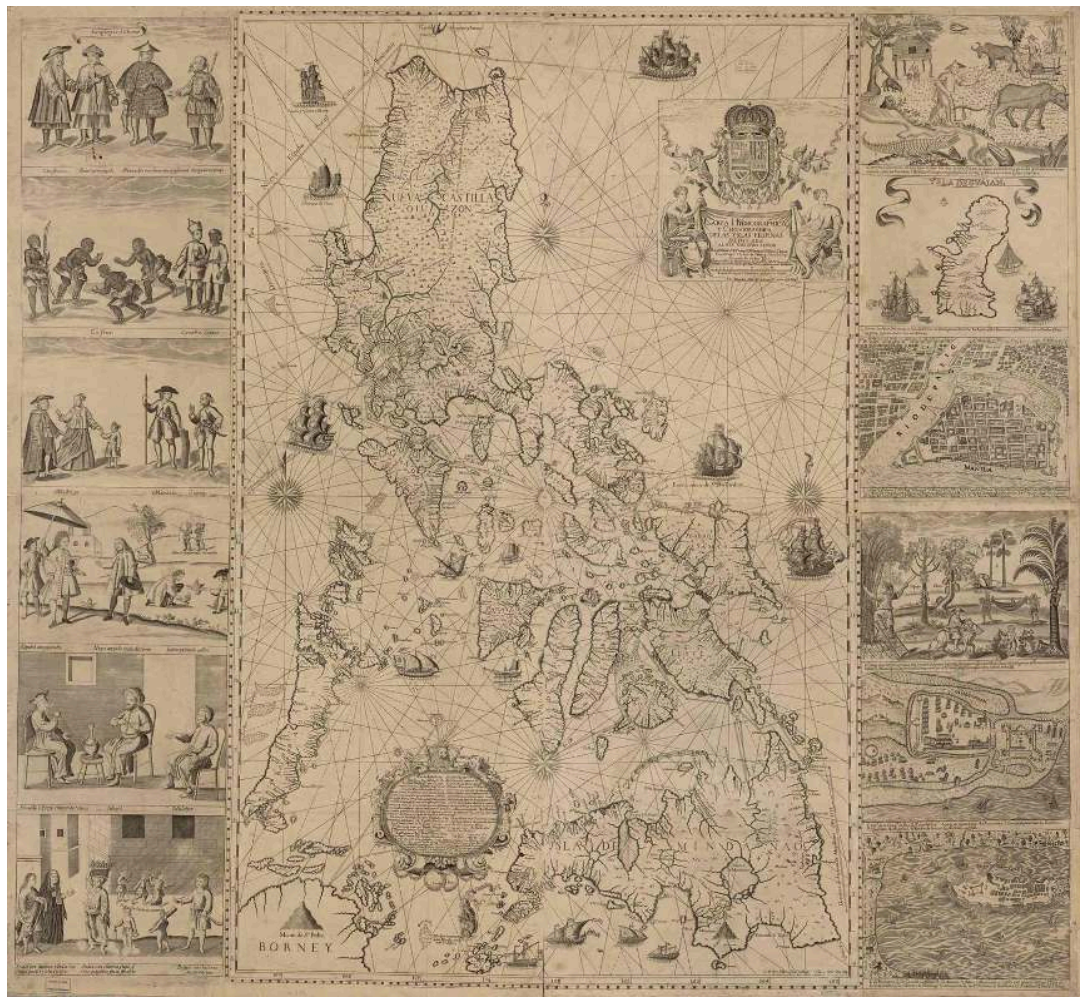

Manila, 1734.Biblioteca Nacional de España, Madrid.

http://www.bne.es/es/Micrositios/Exposiciones/Rizal/resources/img/rizal_000-1_4_1_gr.jpg

2 La fama de la imagen entre los interesados en cartografía de Filipinas ha alimentado el mito de que el mapa de Murillo Velarde representaba el primer mapa jamás de las Islas Filipinas, o a veces el primer mapa impreso en Filipinas mismas. Este mito se ha desvanecido gracias al trabajo de Carlos Quirino, cuyo libro sobre la historia de la cartografía filipina sirve como punto de partida indispensable para cualquier trabajo sobre el tema. Algunas de las islas que ahora conocemos como las Filipinas figuraban en la cartografía china anterior a la llegada de los europeos durante el siglo XVI, y en la cartografía china y japonesa posterior al contacto con Europa. Luego las islas aparecen en mapas manuscritos hechos por varios portugueses, españoles y italianos a lo largo del siglo XVI, y también en mapas impresos, primero italianos y luego holandeses. En todos estos mapas, las Filipinas figuran como parte de una geografía que abarca, como mínimo, toda Insulindia, o a veces toda Asia (dejando a un lado mappaemundi). No es hasta 1598 que tenemos un mapa impreso de las Islas Filipinas solas, el "Insulae Philippinae" de Petrus Kaerius Caelvit, un holandés cuyo mapa de las islas fue incluido en el Caert thresoor inhoudende de tafelen des gantsche werelts, una colección de 165 mapas 
por una serie de cartógrafos ilustres. ${ }^{2}$ Durante el siglo XVII, aparecen algunos mapas mas de Filipinas solas, junto con algunos mapas y vistas de la ciudad de Manila, todos de imprentas holandesas o inglesas, aunque algunos quizás derivados de fuentes españolas. ${ }^{3}$ Mapas hispánicos de las Islas anteriores a Murillo Velarde son escasos, por las mismas razones que son escasos los mapas de otras partes de España y sus posesiones coloniales, pero los mapas que existen son sumamente interesantes. Por la mayoría, representan un intento de conceptualizar el mundo a servicio de los intereses imperiales españoles, y en contra de la tradición geográfica dominante, un intento que hace resaltar la diferencia entre la geografía política que subyace la historiografía moderna, y la que informaba la imaginación imperial española de la temprana modernidad.

3 La expansión española durante aquella época fundamentaba su legitimidad en la autoridad concedida a la corona de Castilla y León por una serie de bulas eclesiásticas, y estas bulas, junto con una serie de tratados internacionales con la corona de Portugal, también imponían límites territoriales sobre aquella expansión. Eventualmente esos límites se configuraron como un meridiano que dividía el globo en dos mitades de naranja, se dice, la una castellana y la otra portuguesa. Infames son los pleitos entre las dos coronas sobre la localización exacta de ese meridiano, tanto en América del Sur como al otro lado del mundo, en Insulindia. En una época en la cual era imposible medir la longitud con precisión, las posiciones de aquellas líneas se fijaban muchas veces no con instrumentos científicos sino con armas de guerra o plumas de abogados. Las Islas Filipinas se encontraban con frecuencia en el meollo de las controversias, junto con Brasil, ya que, según los cálculos de los cosmógrafos portugueses, caían dentro del hemisferio lusitano y la presencia española en ellas representaba una usurpación de los derechos de Portugal. No nos debe sorprender, entonces, que la representación cartográfica de las Islas Filipinas en mapas patrocinados por la corona de Castilla siempre afirman la soberanía de España sobre ellas, y lo hacen mediante la insistencia, de alguna manera o otra, de su pertinencia al hemisferio castellano, y por lo tanto al Nuevo Mundo.

4 Aquella representación empieza con la llegada de los sobrevivientes de la expedición de Magallanes a España en el año 1522. Se produjo durante la década siguiente una serie de mapas archiconocidos que cuentan entre los mas importantes de la presunta "Epoca de los Descubrimientos," ya que todos son copias del mappamundi oficial de la Corona de Castilla, el padrón general mantenido por los cosmógrafos de la Casa de la Contratación en Sevilla. ${ }^{4}$ Por lo tanto, representan los productos cartográficos mas avanzados de su época, en particular con respeto a la geografía del Nuevo Mundo, ya que el padrón general incorporaba los datos que tenían que entregar al regresar a España los viajeros que comerciaban y conquistaban en el extranjero con licencia oficial. Pero también tenemos que recordar, como han mostrado Ursula Lamb, Jerry Brotton, Ricardo Cerezo Martínez, Luisa Martín Merás, Alison Sandman, y otros, que estos mapas eran también herramientas diplomáticas, diseñadas para promover los intereses de Castilla en su conflicto con Portugal sobre la posesión de la Especería. ${ }^{5}$ Por lo tanto casi todos ponen de relieve la línea de la demarcación en el mundo atlántico y el antimeridiano en el mundo asiático. Las islas de la Especería y sus alrededores, incluyendo lo que se conocía de las Filipinas, siempre aparecen al lado izquierdo del mapa, en el extremo occidente. Con estos mapas, entonces, empieza lo que podríamos llamar la occidentalización de 
Filipinas, el intento de cartografiar las islas como el extremo oeste de las Indias españolas.

5 Hay que tomar en cuenta que hablar de "Filipinas" a la altura de le década de los veinte representa un perfecto anacronismo. Aunque la llegada de Magallanes a las islas Visayas en el año 1521 se celebra como el descubrimiento de las Islas Filipinas por Europa, también se puede hablar de una "invención" de las Filipinas que realmente había empezado con la llegada de los Portugueses a Insulindia casi una década antes, y que continuaría a lo largo del siglo dieciséis, a través del labor de toda una serie de viajeros, colonizadores, comerciantes, y cartógrafos. ${ }^{6}$ Un acercamiento de este tipo toma en cuenta el hecho que para la imaginación europea del siglo XVI el archipiélago que ahora conocemos como Insulindia representaba una geografía poco conocida y media imaginada. Algunas islas se conocían a primera mano, y otras solamente por reputación. Lo que se sabía del archipiélago no siempre circulaba, debido a los intereses de los involucrados en el comercio en salvaguardar información que les aventajaba sobre sus competidores. Este aura de misterio hacía posible la supervivencia de expectativas de origen medieval, que existían aún mas islas ricas en oro y especies que las que se conocían, que el archipiélago representaba una cornucopia de riquezas y hasta de maravillas casi inagotable. Cuando se hablaba de "las Malucas" o de "la Especería," generalmente se refería al archipiélago entero, no al grupo de las cinco islas donde se encontraba el clavo, y ni siquiera al grupo mas amplio que cabía dentro del concepto nativo de "Maluku." Aún en la década de los setenta, era posible para el cosmógrafo oficial de las Indias españolas, Juan López de Velasco, escribir lo siguiente sobre Insulindia:

Y aunque cada día se va aclarando más la noticia de estas islas y provincias, hasta agora, por no haberse frecuentado tanto la navegación dellas á causa de estar tan lejos por la una y otra parte de España, que se puede decir que están en fin del mundo y parte opósita della, no están acabadas de descubrir bien todas, ni en general se puede decir del número dellas más, de que es un arcipiélago de más de leguas de largo leste-oeste, y norte-sur; en el cual espacio hay una infinidad de islas grandes y pequeñas, muchas dellas costeadas del todo, y otras que no se han acabado de descubrir ni se sabe si son islas ó tierra firme, entre las cuales hay islas de más de cien y de doscientas y trescientas leguas de boxo, y de ahí abajo, otras muchas de cuenta y nombre, y grande número de islas pequeñas; en las cuales hasta ahora no se sabe que haya más de cuatro poblaciones de españoles, dos de castellanos y dos de portugueses, en que debe haber como quinientos ó seiscientos cristianos, la mitad dellos castellanos y la otra mitad portugueses. ${ }^{8}$

6 A continuación, López de Velasco describe las islas conocidas, reuniéndolas en grupos archipielágicos, entre ellos "Filipinas," pero sus esfuerzos para fijar la taxonomía geográfica de Insulindia representan solamente un principio tentativo, no una observación sobre la realidad. Su mapa de la región, impreso en 1601 en la Descripción de las Indias de Antonio de Herrera y Tordesillas, tiene el aspecto de un borrador. (Figura 2) Aquí noto solamente algunas de sus imprecisiones. La imagen de las Islas Filipinas mismas es sumamente impresionista. Nos deja entender que el grupo incluye una isla grande en el sur, un grupo de islas pequeñas en el centro, y otro territorio grande en el norte, pero no determina los límites de ese territorio, que nosotros reconocemos como la isla de Luzón. La ciudad de Manila aparece en la costa sureña de Luzón, en vez de la occidental. La lista de nombres de las islas contiene una extraña confusión, ya que identifica a una de las islas pequeñas y centrales, la mas occidental del grupo, como "Mindanao," y da el nombre de "Mandana" a la isla grande del sur, la verdadera isla de 
Mindanao. Las isletas hacia el este del grupo, mientras tanto, se representan fuera de escala, de tal manera que esta parte del Pacífico occidental parece estar atravesado por un rosario de islas que facilitan la navegación hacia Filipinas desde el oriente.

Figura 2: "Descripción de las Indias del Poniente," de Antonio de Herrera

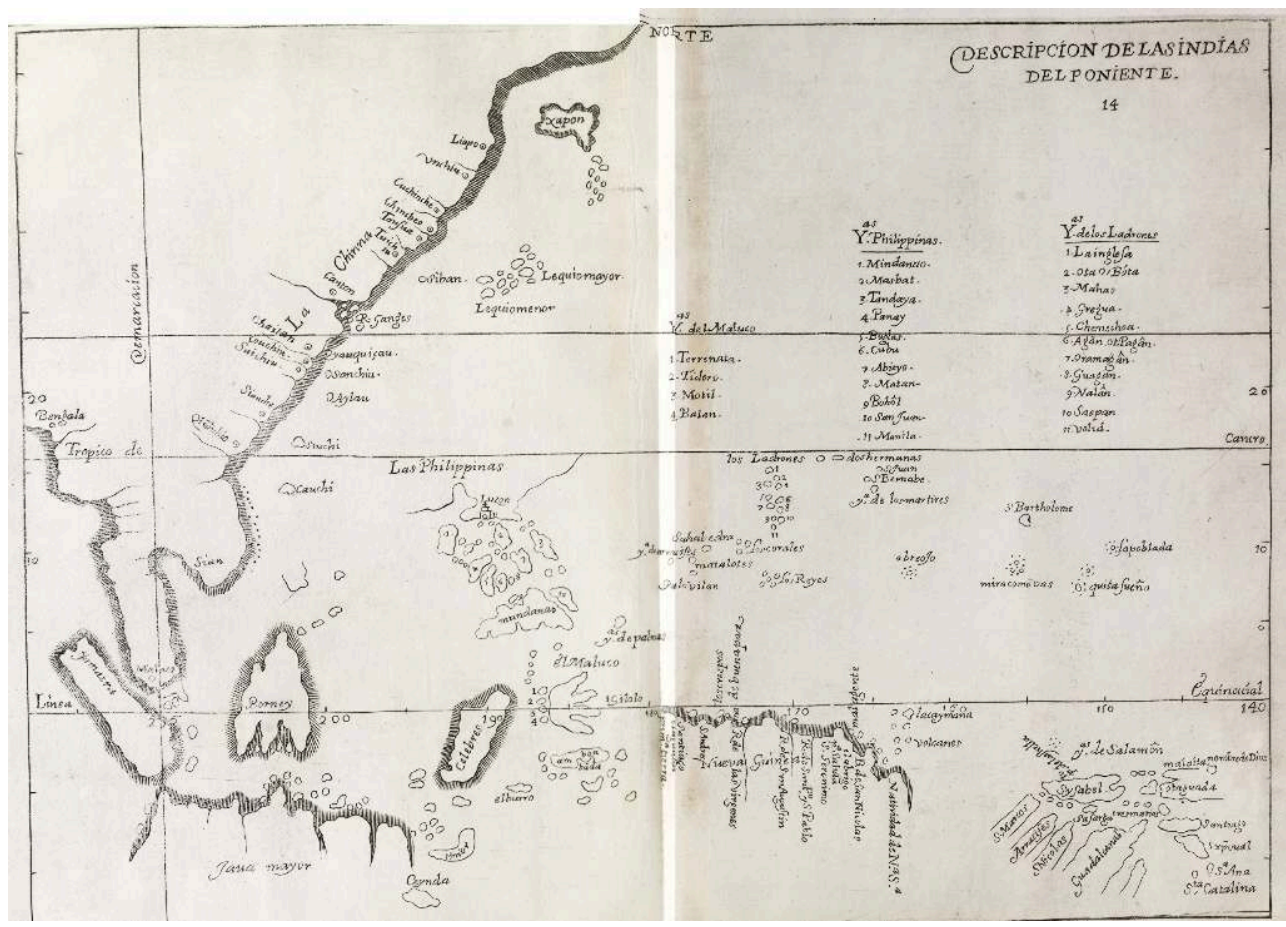

Descripción de las Indias. Madrid, 1601. Wikimedia Commons

HTTP://UPLOAD.WIKIMEDIA.ORg/WIKIPEDIA/COMMONS/3/36/

DESCRIPCION_DE_LAS_INDIAS_DEL_PONIENTE.JPG

Obviamente importa mas la región figurada aquí "Islas del Poniente" que cualquiera de sus componentes individuales, como las Islas Filipinas. Según Jorge Rizal, padre de la independencia filipina, "las Islas del Poniente" era un nombre antiguo de las Islas Filipinas, y de hecho vemos que al principio del siglo XVII habían viajeros que hablaban de "Las Indias Filipinas del Poniente," pero dentro del contexto de la cartografía oficial, el topónimo "Las Indias del Poniente" abarcaba mucho más. López de Velasco traza sus límites de esta manera:

Todas las islas y tierra firme que caen dentro de la demarcación de los Reyes de Castilla, al occidente de las Indias de la Nueva España y Pirú, que se comprenden en $90^{\circ}$ de longitud, y desde $13^{\circ}$ o $14^{\circ}$ de latitud austral, hasta $35^{\circ}$ o $40^{\circ}$ de latitud septentrional. ${ }^{9}$

Esta es la región que vemos representada en el mapa impreso con el libro de Herrera. Aquella "occidentalización" del Oriente que había empezado con los planisferios sevillanos de la década de los veinte se ha llevado a otro nivel de sofisticación. Aunque se trata de un mapa tipo borrador, el avance sobre la representación cartográfica de la zona hecha posible por los viajes de Loaysa, Saavedra y Villalobos queda patente. También está en evidencia una consecuencia del uso de métodos nuevos, aunque imperfectos, para medir la longitud. López de Velasco tiene ahora datos (equívocos, según nuestros criterios) que le permiten trazar el antimeridiano hacia el oeste de donde lo ubican los portugueses, cerca de la ciudad lusitana de Malacca. De esta 
manera, no solamente la Especería sino la China y Cambodia se hacen parte de las "Indias Occidentales," o sea, de aquellas Indias que pertenecían a Castilla y no a Portugal.

Este intento de occidentalizar el Oriente recibe apoyo del mapa general de las Indias Occidentales que también fue impreso con el libro de Herrera, y que también responde a un prototipo manuscrito de la mano de López de Velasco dibujado unos 25 años antes. (Figura 3) Este mapa acorrala las Indias del Poniente (así los llama Herrera, modificando el término usado por López de Velasco) con América dentro de un espacio cartográfico definido mas que nada por las líneas de la demarcación. Tiene el propósito, como he argüido en otro contexto, de investir este conjunto territorial tan arbitrario con cierta coherencia interna. ${ }^{10}$ Para lograr este fin, se han tomado una serie de decisiones que dan a este mapa una ventaja decisiva sobre los planisferios sevillanos. Se ha decidido construir un mapa de las Indias solas, en vez de representarlas en un mappamundi, y de esta manera se ha evitado el obvio inconveniente de tener que representar a las Indias del Poniente como parte de la masa continental de Asia. Se ha manejado la forma y posición gráfica de topónimos para llenar espacios vacíos, creando un puente visual sobre la expansión vacía del Océano Pacífico. Y lo que es más importante, se ha reducido la longitud de aquella expansión. Entre el mapa de Walseemüller de 1507 y el planisferio de Diogo Ribeiro de 1529, vemos un crecimiento en la anchura del Pacífico, de 80 grados de longitud a 134. En el mapa publicado con Herrera, el Pacífico se vuelve a achicar a 110 grados de longitud. ${ }^{11}$ Se produce de esta manera una imagen de las Indias Occidentales como una región continua y trans-Pacífica, que se extiende naturalmente desde una línea de demarcación a la otra, desde el Atlántico a Malacca.

Figura 3: "Descripción de las Indias Occidentales" de Antonio de Herrera

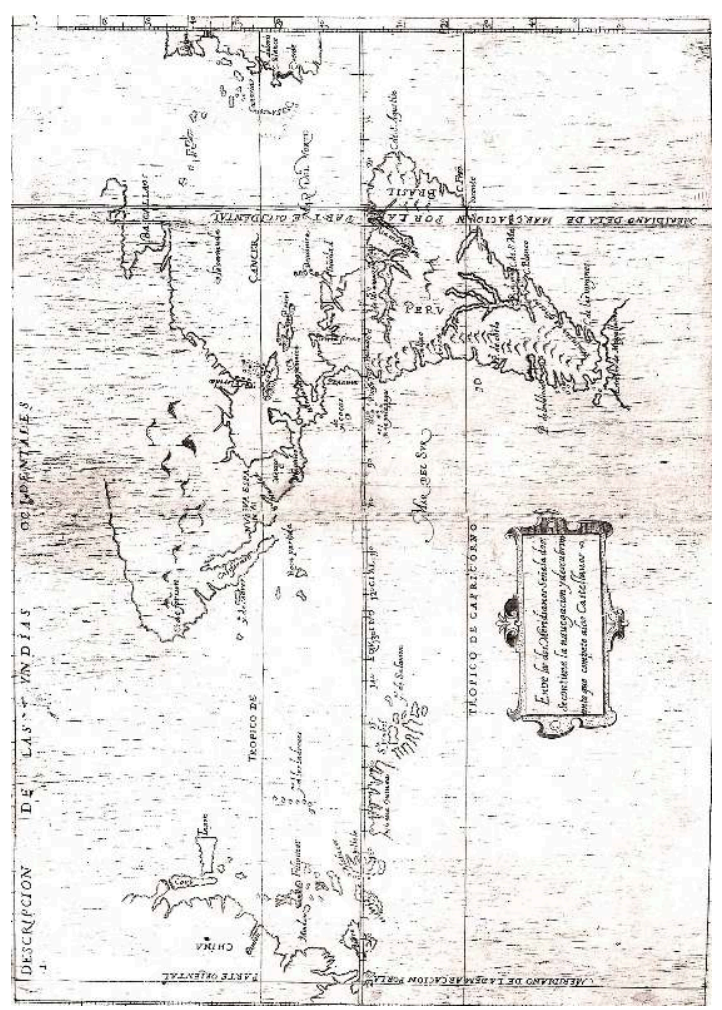

Descripción de las Indias. Madrid 1601. National Library of Australia HTTP://NLA.gOV.AU/NLA.MAP-RM2695 

Como es bien sabido, España no tuvo otro remedio que tratar de llegar a la Especería por el Pacífico, ya que el camino por el Cabo de Buena Esperanza le había sido vedado por el Tratado de Tordesillas. Las mismas condiciones gobernaban sus intentos de gobernar y comerciar con las Filipinas, a partir del establecimiento de su colonia ahí en 1565. Por lo tanto, las Islas Filipinas llegaron a formar parte del Virreinato de la Nueva España, y su único lazo comercial legítimo con la madre patria era el galeón que hacía cada año la travesía entre Manila y Acapulco. Impresiona, sin embargo, el punto hasta el cual el pensamiento oficial español se empeñaba en hacer coherente, al nivel ideológico, este lazo político y económico bastante arbitrario. Es posible que para la mentalidad del siglo XVI el intento no parecía tan forzado como quizás nos parezca a nosotros, ya que en aquella época, como ha mostrado Nicolás Wey-Gómez, importaba mas en la determinación del carácter de un sitio y su gente la latitud que la longitud. Las Indias occidentales y las orientales eran ambas, antes que nada "Indias," lugares que se encontraban dentro de la vieja zona tórrida que durante la temprana modernidad se estaba imaginando de nuevo como el trópico. ${ }^{12}$ De todos modos, a pesar de esta disposición a entender las diferentes partes del trópico como manifestaciones individuales de la misma realidad indiana, había que luchar contra la fuerza centrífuga del Pacífico, con sus espacios tan anchos, tan vacíos, y con la tradición tan antigua de pensar en las Indias como un espacio no solamente hacia el sur, sino también hacia el este - nunca hacia el oeste - de Europa.

11 Es impresionante, también, observar la perseverancia de esta conceptualización, que dura hasta las vísperas de la publicación del mapa de Murillo Velarde. ${ }^{13}$ Se mencionó al principio que este mapa no era el primero en representar las Islas Filipinas. Ni siquiera era el primero fabricado durante el siglo XVII, ya que la "Carta Chorographica de Archipielago de las Islas Philippinas" de Franciso Díaz Romero y Antonio Ghandia, lo anticipó por siete años. (Figura 4) Este mapa un producto de la Armada española, nuevamente profesionalizada en todos sus sentidos, incluyendo el de la producción cartográfica. Representa un avance espectacular en el conocimiento cartográfico de las Islas Filipinas, el cual seguía siendo "penosamente inexacto" y "casi tan vago como siempre" hasta principios del XVII. ${ }^{14}$ A 60 " de largo y 38 " de ancho $(152 \mathrm{~cm}$ x 76cm), era sin duda el mapa mas grande que se había editado en Manila hasta entonces. Era también el relieve de la "Descripción de las Indias del Poniente," ya desde hace décadas obsoleto como mapa de la región, en la tarea de occidentalizar a las Islas Filipinas. En el mapa Romero-Ghandia no figura el antimeridiano de la demarcación, pero cada aspecto de su diseño, incluyendo su escala, su forma y orientación, su estructura interna y su iconografía, queda involucrado en conseguir este propósito.

La escala y las dimensiones físicas del mapa se han seleccionado de tal forma que permitan la representación de las islas con un nivel de detalle bastante alto, pero sin excluir la región circundante. La forma rectangular del mapa, y la orientación transversa, permite la inclusión de otros lugares hacia el este y el oeste, en vez de hacia el norte y el sur, haciendo posible la inclusión de las Islas Marianas, escala crucial en el derrotero del galeón entre Manila y Acapulco. Las Filipinas mismas se encuentran rodeados por un arco toponímico, "Mar del Archipiélago de las Islas Philipinas," que convierte las islas en el centro de una diana que atrae a la mirada. Pero esta diana se ubica a la izquierda del campo visual, de tal manera que la mirada no descansa ahí, sino sea pasea a otros focos visuales, como las armas borbónicas que afirman la soberanía 
española sobre las islas. Las armas forman el ápice de un triángulo cuya base es definida por el cartucho que lleva el título del mapa, a la izquierda, y el que indica la escala del mapa, a la derecha. Ahí la mirada encuentra dos figuras alegóricas, personificaciones de Asia y de América, recuerdos que Filipinas es el sitio de encuentro de estos dos continentes.

Figura 4: Diaz Romero, Francisco, and Antonio Ghandia. 1727. Carta Chorographica de Archipielago de las Islas Philippinas

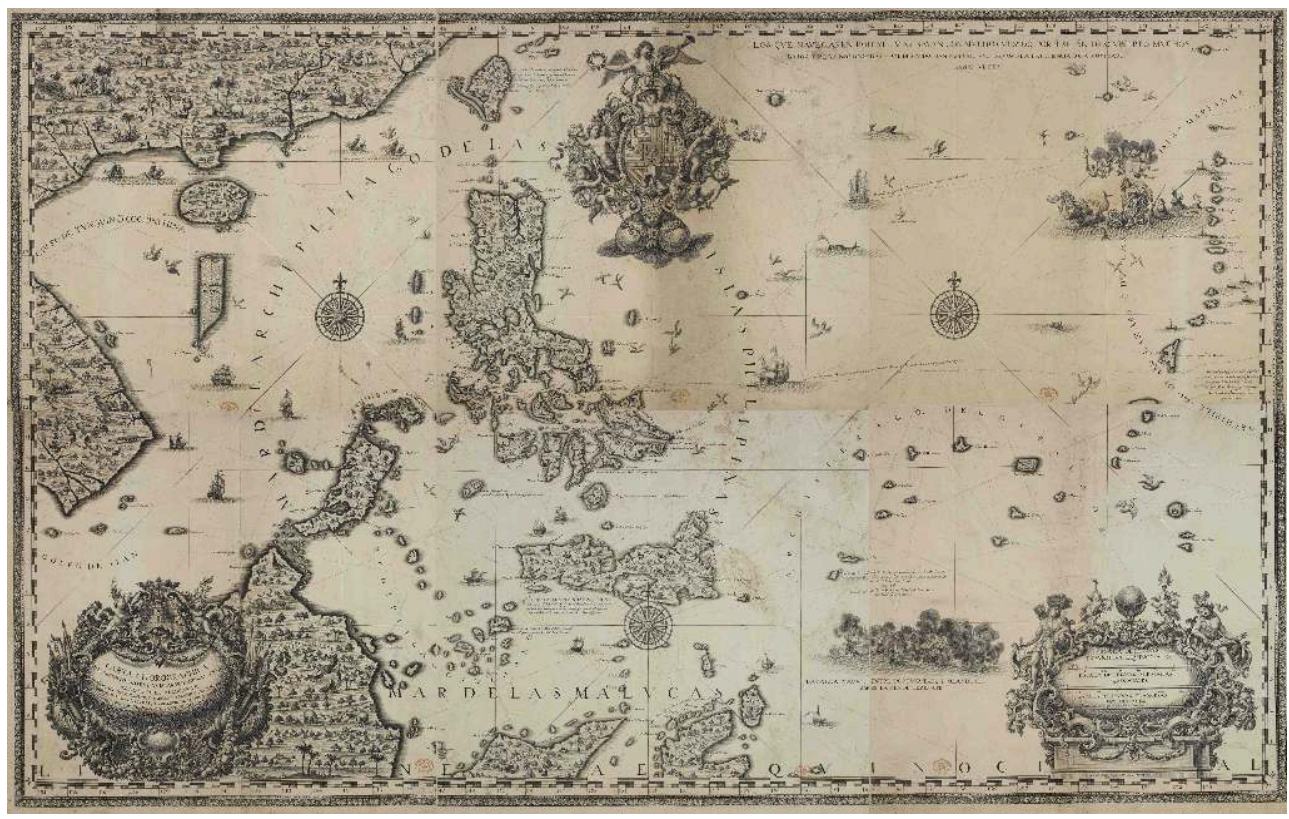

MANILA, 1727

COURTESY OF THE BRITISH LIBRARY

El centro del triángulo formado por las armas y los cartuchos corresponde al centro del campo visual, pero aquí la mirada no encuentra nada. Desde ahí, es natural pasearse hacia el noreste, siguiendo el camino delineado por el arco de islas y la serie de barcos y animales hasta encontrarse con la figura alegórica a la derecha superior. Aquí se descubre la Fé personificada navegando hacia el oeste desde las Marianas, y por implicación desde América, en un carro tirado por leones españoles y decorado con un escudo real. La alegoría nos recuerda que la Fé llegó a Filipinas a través del Pacífico, junto con el poder español. De esta manera el mapa inscribe su imagen cartográfica de las Islas Filipinas dentro de una alegoría visual de la historia que las ha atado en sentido religioso y político a la América española. Aunque las islas mismas aparecen en el lado izquierdo del mapa, donde domina la tierra sobre el mar, pertenecen al mundo representado por el lado derecho, donde domina el mar sobre la tierra. 0 sea, aunque las Islas Filipinas se encuentran en Asia, pertenecen al mundo trans-pacífico de las Indias Occidentales. El círculo de soberanía descrito por el arco "Mar del Archipiélago de las Islas Philipinas" forma el último eslabón en la cadena de círculos que se extienden hacia el oriente, que incluyen, explícitamente, el "Archipiélago de Palaos" y el “Archipiélago de San Lázaro o las Islas Marianas," y implícitamente, América.

Ahora, si este mapa servía tan bien para occidentalizar a las Islas Filipinas, y de esta manera afirmar la soberanía de España sobre ellas, ¿porqué fue remplazado en tan poco tiempo por otro? Seguro que por varias razones tanto prácticas (la necesidad de una 
carta marítima útil) como ideológicas. Entre ellas sabemos que figuraban las fallas en la representación de la isla de Mindanao, la cual aparece dibujada de una forma demasiado rectangular y sin una de sus principales islas vecinas. ${ }^{15}$ Esta isla también queda mal incorporada al resto del archipiélago filipino. No queda del todo dentro del círculo imaginario sugerido por el arco toponímico que nombra las Filipinas, haciendo posible que la isla se perciba como la región fronteriza que de hecho era y sigue siendo. Esta impresión encuentra apoyo en la distancia exagerada que separa a Mindanao de las islas Visayas hacia el norte, y la atracción magnética del topónimo hacia el sur, "Mar de las Maluccas." El mapa de Romero y Ghandia, por lo tanto, triunfa en el labor de occidentalizar a las Islas Filipinas, pero fracasa en aquel otro labor de definirlas como un mundo insular íntegro, claramente distinguible de los otros archipiélagos de Insulindia.

Por contraste, en este labor triunfa completamente el mapa de Murillo Velarde, el cual sustituyó al de Romero y Ghandia como mapa oficial de las islas. (Figura 1) Podemos suponer que la decisión de dedicar el espacio de representación entero a las Filipinas, dejando afuera países cercanos, correspondía a la necesidad de figurar su hidrografía a una escala adecuada para las exigencias de la navegación, pero también nos damos cuenta inmediatamente que esta decisión también tenía una consecuencia ideológica obvia. Las Islas Filipinas aparecen como un archipiélago íntegro. Apenas nos damos cuenta de la banderola que se encuentra en el estrecho entre Mindanao y las Visayas, y que reza "Desde Samboangan hasta Caraga por el norte es de España," dando testigo a las limitaciones de la soberanía española práctica en el sur de Mindanao. Nos llama la atención, por contraste, el hecho de que Mindanao queda divorciado de sus vecinas hacia el sur por el borde del mapa, que la distancia entre esta isla y las Visayas ha sido reducida, y que la costas de Mindanao cuadran de una manera muy grata con el rincón del mapa. La isla se convierte, no solamente en una parte íntegra del archipiélago, sino en una especie de base visual para todo el conjunto de sus islas.

Por otra parte, este mapa hace poquísimo para occidentalizar a las Filipinas. No aparecen ni las Islas Palau ni las Marianas. Su iconografía no incluye ningún recuerdo de América o de la llegada del poderío español desde la orilla oriental del Pacífico. Se trazan varios derroteros marítimos, pero estos no sirven para atar a Filipinas con América, sino para figurar su relación multifacético con el resto del mundo. El primero es la ruta de Magallanes por las islas en su viaje de descubrimiento, el segundo el derrotero que actualmente seguía el galeón de Manila, el tercero un derrotero alternativo para el mismo, y el cuarto la ruta hacia la costa de Asia y a España por el Cabo de Buena Esperanza. El derrotero de Magallanes marca el descubrimiento de Filipinas por Europeos, y por lo tanto el momento en que las islas entraron en la única historia que contaba para los fabricadores y consumidores de este mapa, pero aquel derrotero indica tanto la llegada de Magallanes desde el Pacífico y la salida de los sobrevivientes para Maluku, y por lo tanto inserta a las Filipinas en una trayectoria global, no meramente trans-pacífica. Luego, dos derroteros mas enfocan el problema local, y no el carácter trans-pacífico del viaje del galeón. Su tema es la seguridad del galeón dentro del archipiélago, no su función como lazo político, cultural y económico con la Nueva España. Y el derrotero hacia Asia y España forma un contrapunto geográfico a todo el tema del galeón y la relación con Acapulco. Luego, el galeón no es el único barco que aparece representado en el mapa. También figura un sampán chino y el paquete de Macao, que a su manera marcan los lazos importantes, ambos culturales y económicos, que unían a Filipinas con la China y con el imperio portugues. El puerto de 
Cavite y la isla de Guam, puntos claves en le derrotero del galeón, quedan relegados a las imágenes marginales, sacadas de su contexto como puertos en la ruta trans-pacífica. El resto de las imágenes se preocupan de temas netamente filipinos, como son su vida urbana y campestre, y el carácter cosmopolita - pero marcadamente asiático - de sus habitantes. Aquí, en los cuadros que representan la voz, no del jesuita a cargo del proyecto, sino la de su colaborador filipino, Filipinas no forma parte de América, o de las Indias. Representa un mundo aparte, independiente en sentido cultural y económico, aunque no en el político, de aquellas de otras partes de la Monarquía Hispánica.

17 Ahora, no quiero sugerir que este mapa representa un primer grito de independencia, ni mucho menos, ya que se trata todavía de un mapa autorizado por la Corona, uno que llegó a disfrutar de autoridad canónica, aún durante el período colonial. Se trata mas bien de una transformación en la concepción de Filipinas que correspondía a un cambio en la concepción del territorio de la Monarquía en total. Por varias razones, la geografía española abandonó el viejo concepto de las Indias como una entidad trans-Pacífica. Aunque las Islas Filipinas seguían formando parte del Virreinato de Nueva España, y seguían ligadas a México por el galeón de Manila, la cartografía española por fin adoptó el modelo geográfico que había llegado a dominar el pensamiento europeo mucho antes, uno que distinguía nítidamente entre un Nuevo y un Viejo Mundo, uno que trataba de "América" en vez de las Indias trans-pacíficas. En los principales proyectos cartográficos españoles del siglo de las luces, como la cartografía de Juan de la Cruz Cano o la geografía de Tomás López, vemos que se trata de América sin jamás tomar en cuenta las Indias que ya se estaban olvidando - o sea, que se estaban dejando fuera de proyectos cartográficos monumentales - las Islas Filipinas.

Ahora, sin embargo, creo que nos hace falta recuperar el lugar de las Indias olvidadas en la historia que nos contamos de la cartografía de América Latina, o en América Latina. La cartografía, como nos han enseñado Denis Wood, J. Brian Harley, David Woodward y muchos otros, no representa sino inventa, y esto lo hace inevitablemente según los prejuicios culturales y los intereses ideológicos de la gente que la produce y consume. Cuando dibujamos mapas de "Latinoamérica" y aún de "América" misma, manejamos conceptos metageográficos acuñados en determinados momentos, a partir de determinadas condiciones materiales y ideológicas, conceptos que luego han sido deformados y reformados en servicio de otros momentos, otros intereses. Me sorprende, sin embargo, como se suele olvidar de aquellas Indias olvidadas que durante tanto tiempo constituían, en la imaginación imperial española, uno de los dos extremos de una metageografía que pocas veces se toma en cuenta, el concepto de las Indias como un territorio hemisférico y trans-pacífico. Aquel concepto se nos manifiesta como una especie de espectro recordándonos que América no fue inventada de golpe en 1507 cuando Waldseemüller sacó su mappamundi tan famoso, que este concepto tan fundamental para lo que hacemos nosotros competía con otro mapeamiento que trataba de mantener unido lo que Waldseemüller había separado. Si aquel concepto queda olvidado, no es porque era menos arbitrario que cualquier otro, sino porque el poder imperial español nunca cumplió con su sueño de hacer de las Indias transpacíficas una realidad política que incluía no solamente a Filipinas sino a China también, y porque la modernidad, después de todo, no aprendió a concebir el mundo de mapas españoles. 


\section{BIBLIOGRAFÍA}

Andaya, Leonard Y. The World of Maluku: Eastern Indonesia in the Early Modern Period. Honolulu: University of Hawaii Press, 1993.

Brotton, Jerry. Trading Territories: Mapping the Early Modern World (Reaktion Books - Picturing History). Reaktion Books, 2004.

Cerezo Martínez, Ricardo. La cartografía nautica española en los siglos XIV, XV, y XVI. Madrid: CSIC, 1994

Lamb, Ursula. "Science by Litigation: A Cosmographic Feud." Cosmographers and Pilots of the Spanish Maritime Empire. Brookfield, VT: Variorum, 1995. 1 (1969): 40-57.

López de Velasco, Juan, and Marcos Jiménez de la Espada. Geografía y descripción universal de las Indias. Biblioteca de autores españoles 248. Madrid: Atlas, 1971.

Martín-Merás, Luisa. Cartografía marítima hispánica: La imagen de América. Madrid: Lunwerg for Ministerio de Obras Públicas, Transportes y Medio Ambiente, 1992.

Padrón, Ricardo. "A Sea of Denial: The Early Modern Spanish Invention of the Pacific Rim." Hispanic Review 77, no. 1 (2008): 1-27.

Quirino, Carlos. Philippine Cartography, 1320-1899. Vol. 2. Amsterdam,: N. Israel, 1963.

Sandman, Alison. "Cosmographers vs. Pilots: Navigation, Cosmography, and the State in Early Modern Spain." University of Wisconsin, History of Science, 2001.

Wey Gómez, Nicolás. The Tropics of Empire: Why Columbus Sailed South to the Indies. Cambridge, Mass.: MIT Press, 2008.

Wroth, Lawrence C. "The Early Cartography of the Pacific." The Bibliographical Society of America, Papers 38 (1944): 87-268.

\section{NOTAS}

1. Carlos Quirino, Philippine cartography, 1320-1899, vol. 2 (Amsterdam,: N. Israel, 1963), 61.

2. Ibid., 2:39.

3. Ibid., 2:79-87.

4. Véase Luisa Martín-Merás, Cartografía marítima hispánica: La imagen de América (Madrid: Lunwerg for Ministerio de Obras Públicas, Transportes y Medio Ambiente, 1992), 69-158.

5. Ursula Lamb, "Science by Litigation: A Cosmographic Feud," Reprinted in Cosmographers and Pilots of the Spanish Maritime Empire. Brookfield, VT: Variorum, 1995. 1 (1969): 40-57; Jerry Brotton, Trading Territories: Mapping the Early Modern World (Reaktion Books - Picturing History) (Reaktion Books, 2004); Ricardo Cerezo Martínez, La cartografía nautica española en los siglos XIV, XV, y XVI (Madrid: CSIC, 1994); Martín-Merás, Cartografía marítima hispánica: La imagen de América; Alison Sandman, "Cosmographers vs. Pilots: Navigation, Cosmography, and the State in Early Modern Spain" (University of Wisconsin, History of Science, 2001).

6. Para la invención de las Filipinas en la escritura y cartografía ibérica, véase Rodrigues Lourenço, Miguel. "De São Lázaro às Filipinas: imagens de um arquipélago na cartografia náutica ibérica doséculo XVI." In Mapas de metade do mundo : a cartografia e a construção territorial dos espaços americanos, séculos XVI a XIX = Mapas de la mitad del mundo : la cartografía y la construcción 
territorial de los espacios americanos, siglos XVI al XIX, Edited by Francisco Roque de Oliveira and Héctor Mendoza Vargas. (Lisbon and Mexico: Centro de Estudos Geográficos, Universidadede Lisboa ; Instituto de Geografía, Universidad Nacional Autónoma de México, 2010.) 387-422.

7. Véase Leonard Y. Andaya, The World of Maluku: Eastern Indonesia in the Early Modern Period (Honolulu: University of Hawaii Press, 1993), 23-112

8. Juan López de Velasco and Marcos Jiménez de la Espada, Geografía y descripción universal de las Indias, Biblioteca de autores españoles 248 (Madrid: Atlas, 1971), 289.

9. Ibid

10. Ricardo Padrón. "A Sea of Denial: The Early Modern Spanish Invention of the Pacific Rim." Hispanic Review (77, no. 1 [2008]: 1-27.).

11. Lawrence C. Wroth, "The Early Cartography of the Pacific," The Bibliographical Society of America, Papers (38 [1944]: 151).

12. Nicolás. Wey Gómez, The Tropics of Empire: Why Columbus Sailed South to the Indies (Cambridge, Mass.: MIT Press, 2008).

13. El salto desde 1601 hasta el Siglo de las Luces es inevitable, dada la penuria de mapas de Filipinas provenientes de fuentes españolas hechas durante el siglo de intervalo.

14. Quirino, Philippine cartography, 1320-1899, 2:45.

15. Ibid., 2:45.

\section{RESÚMENES}

Ya que las Islas Filipinas fueron colonizadas desde América, y fueron gobernadas durante mas que dos siglos desde el Virreinato de la Nueva España, la cartografía imperial española de esta colonia lejana solía representarla como parte de un mundo trans-pacífico, atada a la imagen cartográfica del Nuevo Mundo. Este intento involucraba otro mas ambicioso de considerar a lo que normalmente llamamos las Indias Orientales como el extremo occidente del hemisferio hispánico, un proyecto que se puede identificar en mapas imperiales realizados entre la llegada de Magallanes a las islas filipinas hasta la primera mitad del siglo XVIII. Aquí se analizan las estrategias gráficas utilizadas por este proyecto de "occidentalización cartográfica."

Como as Ilhas Filipinas foram colonizadas a partir da América, e foram governadas durante mais de dois séculos desde o Vice-Reino da Nova Espanha, a cartografia imperial espanhola desta colônia distante costumava representa-la como parte de um mundo trans-pacífico, vinculado a imagem cartográfica do Novo Mundo. Esta tentativa envolveu uma outra mais ambiciosa de considerar o que é comumente chamado de Índias Orientais como o extremo ocidente do hemisfério hispânico, um projeto que pode ser identificado nos mapas imperiais feitos entre a chegada de Magalhães nas Ilhas Filipinas até a primeira metade do século XVIII . Aquí se analisam as estratégias gráficas utilizados por este projeto de "ocidentalização cartográfica".

Since the Philippine Islands were colonized from America, and were governed over the course of more than two centuries from the Viceroyalty of New Spain, Spanish imperial cartography tended to represent this distant colony as part of a trans-Pacific world, tied cartographically to the New World. This effort was part of a larger project of considering what we ordinarily call the East Indies as the extreme west of a Spanish hemisphere. This project appears on imperial maps constructed between Magellan's arrival in the Philippines and the first half of the eighteenth 
century. This article analyzes the graphic strategies used by this project of "cartographic westernization."

\section{ÍNDICE}

Índice cronológico: 1500-1800

Índice geográfico: Filipinas, América

Palavras-chave: Filipinas, cartografia imperial espanhola, Trans-Pacífico, Antonio de Herrera y Tordesillas, Juan Lopez de Velasco, Antonio Romero-Ghandia, Pedro Murillo Velarde

Keywords: Philippines, Spanish imperial cartography, Trans-Pacific, Antonio de Herrera y Tordesillas, Juan Lopez de Velasco, Antonio Romero-Ghandia, Pedro Murillo Velarde Filipinas, America

Palabras claves: Filipinas, Cartografía imperial española, Trans-Pacífico, Antonio de Herrera y Tordesillas, Juan López de Velasco, Antonio Romero-Ghandia, Pedro Murillo de Velarde

\section{AUTOR}

\section{RICARDO PADRÓN}

Professor do Departamento de Espanhol, Italiano e Português na University of Virginia 